\title{
PRESENTATION
}

\section{Thematic Section: Psychological Assessment}

This issue of the journal Estudos de Psicologia (Campinas) includes a thematic section on Psychological Assessment raising important questions about this field that has been steadily increasing in Brazil, especially in recent decades. Although the field has historically been a target of inquiring, there has been some action towards its development fostered by the introduction of Resolution $n^{\circ}$ 002/2003 by the Federal Council of Psychology, with the creation of the Sistema de Avaliação dos Testes Psicológicos (Satepsi, Psychological Testing Assessment System) and by the fact that the year 2011 was declared to be The National Year of Psychological Assessment. Since then, important advances have been made seeking better methods, techniques, and assessment instruments.

The main focus is the need for instruments with greater validity and reliability and that are frequently updated, mainly because the field of testing is restricted to psychologists only. The main issue concerns the validity and development of national psychological assessment instruments in order to change a situation that has lasted years, i.e., the use of psychological instruments without scientific evidence of their psychometric properties. They were often used only to meet practical needs or because of a trend or fad. This situation has led to distrust and disbelief in this field.

There is no doubt about the importance of these actions in the field of psychological assessment, especially those towards the recognition of this field and the discussion of its scientific, practical, and ethical bases. However, practicing professionals should complement these actions towards the development of the psychological assessment field. The assessment and the choice of instruments, methods, and techniques remains the responsibility of psychologists as part of their professional practice. Thus, such choice should be based on the use of evidence-based quality assessment tools. Similarly, there is a need for proper and more comprehensive training and education of students, as well as continuous training of professionals to promote professional development. A continuous improvement process is essential.

Six articles were selected to compose this section. The introductory article, by Paula Elosua, addresses the advances, projects, and international guidelines related to the use of psychological assessment tests. The article presents a review of the best practice guide to the use of the tests, highlighting the importance of a test committee and norms to improve their use in the international context.

Four of those articles introduce new instruments and present results of the assessment of their psychometric properties. The second article, by Acácia Aparecida Angeli dos Santos and Thatiana Helena de Lima, aims to examine construct validity for a phonological awareness measure, presenting exploratory and confirmatory factor analysis results.

In the third article, Lucas de Francisco Carvalho and Catarina Possenti Sette investigated the psychometric properties of a dimensional clinical personality inventory. The article includes the results of studies investigating validity evidence (construct and external criterion) and reliability of the instrument.

The fourth article, by Evandro Morais Peixoto and Elisa Medici Pizão Yoshida addresses the psychometric properties of an adaptive diagnostic scale. The article includes the results of different studies, including 
evidence of internal structure validity, evaluation of the item parameters, and participants' characteristics through the use of the Item Response Theory and the establishment of interpretative norms for the scale.

The fifth article, by Marina Isabel Vieira Antunes Cunha, Ana Maria de Jesus Xavier, Sofia de Miranda Zagalo and Marcela Salomé Albuquerque Andrade de Matos, also presents the results of a number of studies assessing the impact of traumatic events during adolescence. Factor Analysis was used to assess construct validity and convergent validity with measures of centrality of shame memory and symptoms of depression, anxiety, and stress. Internal consistency and temporal stability reliabilities were also reported.

The section ends with the article by Michele Marinho da Silveira and Mirna Wetters Portuguez, which focused on the psychological assessment of a specific and little investigated population, older adults. Through the analysis of life quality and prevalence of cognitive decline, anxiety, and depressive symptoms in older adults, issues related to this developmental stage are discussed.

We hope that the studies presented in this section can encourage students, teachers, researchers, and professionals as they address issues related to teaching, research, and psychological assessment. Moreover, it is expected that these studies, which were carried out in different contexts that encompass this profession, can exemplify the interdisciplinarity of this science.

Profa. Dra. Tatiana de Cássia Nakano

Associate Editor

Pontifícia Universidade Católica de Campinas,

Centro de Ciências da Vida, Programa de Pós-Graduação em Psicologia como Profissão e Ciência 